General Infirmary, January 10th, 1895. He gave the history of having been well up to five years before, when he began to have pain after food and vomiting, but he did not remember having vomited blood. His symptoms continued off and on until June, 1894, when he ceased work and sought advice. Between Christmas, 1892, and January, 1895, his weight diminished from 9 st. 5 lbs. to $7 \mathrm{st} .5 \mathrm{lbs}$.

On admission he was much emaciated, and the signs of dilated stomach were well marked. After taking food he had no rest until vomiting occurred; the vomit was sour smelling and yeasty but never contained bile or blood. He suffered much, not only from painful cramps in the extremities, which required morphine for their relief, but also from distressing spasms of the stomach, which could be distinctly felt contracting, the outline of the dilated organ showing through the abdominal walls. At times a sausage-shaped hard swelling could be felt a little above and to the right of the umbilicus; but as this was only occasionally felt, it was manifestly a contracting pylorus and not a permanent tumour. The stomach was washed out daily and the patient fed with peptonised food, but as all food produced pain and was rejected, rectal feeding was adopted. January 24th. Pyloroplasty was performed through an incision 3 inches long in the linea alba above the umbilicus. The pylorus was found to be surrounded by adhesions and tucked up to the under surface of the liver; its outer surface was puckered as if an alcer had approached the peritoneal coat and had then healed without perforation. On opening the stomach close to the pylorus it was found that the pyloric orifice was contracted to the size of a No. 6 catheter, and that it was surrounded by cicatricial tissue. No shock followed the operation, and the after-progress was all that could be desired. Feeding by the mouth was begun on January 26 th and the rectal feeding discontinued on January 29th. After the sickness due to the anæsthetic had passed off there was no further vomiting. The sutures were removed on the seventh day, when the wound was found to be healed. He rapidly gained flesh, and was discharged well and strong on March 2nd, having gained nearly a stone in weight, and being able to take ordinary food in full meals.

CAsE Ir.-W. F., aged 52, sent to me by Dr. Cheeswright, of Rotherham, on account of vomiting and loss of flesh, was admitted to the Leeds General Infirmary in the first week of April, 1895. He gave the history of indigestion for two years, but of being otherwise fairly well up to Christmas, 1894, when he began to have pain about two hours after food, which was at times followed by vomiting. The vomiting recurred every other day, when a large quantity of mucus and partlydigested food would be rejected. The vomit at first contained dark blood, though during the month before admission no blood had been noticed. During the early part of his illness there was marked tenderness over the epigastrium, but before admission the tenderness disappeared. He was not weighed until five weeks before admission, but in that short time he had lost a stone and a-half in weight.

On admission he had a starved look, and was feeble generally. The signs of dilated stomach were well marked, but no distinct tumour could be felt in the region of the pylorus. There were no other signs of disease. The stomach was washed out daily with a solution of boracic acid, and on April 8th pyloroplasty was performed through an incision 3 inches long in the middle line above the umbilicus. On exposure, the pylorus was found to be much thickened and surrounded by adhesions, which fixed it firmly to the under surface of the liver. After detaching adhesions it could be brought down sufficiently far to be manipulated. On making the longitudinal incision through the pylorus the channel was found to be surrounded by cica. tricial material, leaving a passage which would only admit a No. 10 catheter. The operation, with the use of the bone bobbin, was performed as shown in the diagrams. The afterprogress was perfectly satisfactory, and he began to take food by the mouth on the second day. In the second week he was taking solid food freely, and before 'going home at the month end he was eating large meals of the ordinary hospital diet. He never vomited after the operation, and the wound healed by first intention. When he left for home he had gained half a stone in weight and looked well.

With a little manipulative dexterity, the operation pyloroplasty can be done so quickly and with so little exposure of viscera that post-operative shock need hardly be feared, and as the incision through the pylorus is through cicatricial tissue there is little or no fear of hæmorrhage; in fact, in the two cases related, not a single ligature was required. The only difficulty, and it is one which may usually be expected in these cases, is that the pylorus has to separated from adhesions set up by the inflammatory process which has caused the stricture. These are better separated by the fingers than by a cutting instrument.

It will be found to facilitate the application of the sutures if the longitudinal incision through the pylorus is made rather nearer the lower margin, so that when the slit is sutured transversely the upper angle is well within view. As regards sutures, fine catgut is the best for uniting the mucous margins and fine silk for the serous surfaces.

For simple stricture of the intestine $I$ have found the same operation to prove equally satisfactory.

\section{HUNTERIAN LECTURES}

ON THE

\section{EXPERIENCE OF ST. GEORGE'S HOSPITAL IN LAPAROTOMY;}

\section{EXCLUSIVE OF GYN ACOLOGICAL OPERATIONS,} FROM 1888 TO 1894 INCLUSIVE.

Delivered at St. George's Hospital Medrcal School

BY T. HOLMES, F.R.C.S. Consulting Surgeon and Treasurer to the Hospital.

Lecture III.-Gastrojrjunostomy : Internal StrangulaTION AND STRICTURE OF BOWEL. Conclusion.

THE operation of gastrojejunostomy appears to mark another real advance in surgery, attaining without inordinate risk in cases of pyloric obstruction the object which surgeons have long pursued, but with little success, by gastrostomy, in cases of cesophageal obstruction, namely, the prolongation of life in tolerable comfort and with the power of taking natural food. And I believe that this operation has been so successful that it has displaced or will displace the complicated and dangerous procedure of pylorectomy.

Our experience of gastrojejunostomy during the period covered by these notes has consisted of four cases, in three of which complete success was obtained. The fatal case was that of a woman, under Mr. Haward's care, advanced in life (aged 75) and suffering from cancer in the groin as well as in the stomach. She died on the fifth day after the operation. The necropsy furnished this interesting specimen, which shows the small but adequate artificial communication provided by the operation and also the total disappearance of the Senn's bone plates used to approximate the viscera.

In the successful cases one of the most satisfactory features was the rapidity with which the patient recovered appetite, strength, and flesh. Thus in a case under Mr. Bennett's care in 1891, published in Clin. Trans., xxiv., 247, the patient had been suffering from nearly or quite complete obstruction of the pylorus and was in the last stage of emaciation. The operation was performed on February 27 th, and he was dis. charged on April 23rd. During these two months he had increased $2 \frac{1}{2}$ stone in weight. I may notice here that his weakness was so extreme that it was necessary to feed him by the mouth even on the evening of the operation, when egg and brandy was given, and he was ordered small doses of brandy and milk at frequent intervals during the night. This man died in the country about nine months after the operation from secondary deposit of cancer in the lung.

Another of the patients, also under Mr. Bennett's care, is since dead, having survived the operation rather more than eight months. The case was not an encouraging one, for the malignant mass was not confined to the stomach -in fact, did not originate there, but spread from the umbilicus, where there was a mass of hard cancer, which passed inwards, 
TABLE I.-Laparotomy for Intussusception-All Fatal.

\begin{tabular}{|c|c|c|c|c|}
\hline Name. & Age. & Dite. & Surgeon. & Remarks. \\
\hline $\begin{array}{l}\text { 1. W. } 8 . \\
\text { E. B. } \\
\text { 3. F. I. } \\
\text { 4. L. M. } \\
\text { 5 K. H. }\end{array}$ & $\begin{array}{l}5 \mathrm{~m} . \\
16 \mathrm{~m} . \\
5 \mathrm{~m} . \\
4 \mathrm{~m} .\end{array}$ & $\begin{array}{l}\text { Sept., } 1890 \\
\text { Mar., } 1891 \\
\text { Apr., } 1891 \\
\text { Apr., 1:92 } \\
\text { Apr., } 1893\end{array}$ & $\begin{array}{l}\text { Mr. Bennett } \\
\text { Mr. Pick } \\
\text { Mr. Dent } \\
\quad \text { "- }\end{array}$ & $\begin{array}{l}\text { The intussusception could not be disengaged. An artificial anus formed. } \\
\text { Intussusception easily reduced, but recurred in two days. Again reduced, but the child sank. } \\
\text { The gut burst in the attempt to disengage the intussusception. } \\
\text { Barker's operation for resection of intussuscepted bowel. Sank immediately. } \\
\text { The intussusception was not found till after death, which followed } 3 \text { hours after laparotomy. }\end{array}$ \\
\hline
\end{tabular}

TABLE II.-Laparotomy for Kink and Volvulus.

\begin{tabular}{|c|c|c|c|c|c|c|}
\hline Name. & Age. & Date. & Nature of Case. & Surgeon. & Result. & Remarks. \\
\hline $\begin{array}{l}\text { 1. J. W. } \\
\text { 2. E. } \mathbf{M} \text {. } \\
\text { 3 H. } \mathbf{H .} \\
4 \text { J. B. }\end{array}$ & $\begin{array}{l}36 \\
30\end{array}$ & $\begin{array}{l}\text { July, } 1893 \\
\text { Jan., } 1890 \\
\text { Apr., } 1890 \\
\text { Aug., } 1894\end{array}$ & 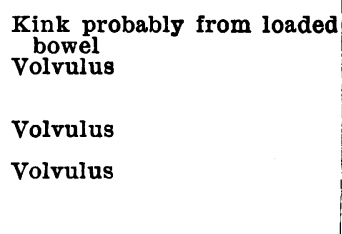 & $\begin{array}{l}\text { Mr. Rouse } \\
\text { Mr. Turner } \\
\text { Mr. Bennett } \\
\text { Mr. Dent }\end{array}$ & $\begin{array}{l}\text { R. } \\
\text { D. } \\
\text { D. } \\
\text { D. }\end{array}$ & $\begin{array}{l}\text { Recovery delayed by suppurative parotitis. } \\
\text { There was also a large intussusception, caused by an intestinas } \\
\text { polypus. This was disengaged, but she never. rallied from } \\
\text { operation. } \\
\text { Cause of obstruction not made out at operation. There was a } \\
\text { volvulus near the commencement of the ileum. } \\
\text { The operation was abandoned; the colon being found to be in a } \\
\text { gangrenous condition. There was a volvulus of the sigmoid } \\
\text { flexure. Operation immediately on admission, but too late. }\end{array}$ \\
\hline
\end{tabular}

TABLE III.-Laparotomy for Strangulation by Bands.

\begin{tabular}{|c|c|c|c|c|c|c|c|}
\hline Name. & Age. & Date. & Nature of Case. & $\begin{array}{l}\text { Dura- } \\
\text { tion. }\end{array}$ & Surgeon. & Result. & Remarks. \\
\hline 1. R. P. & 47 & Dec., 1888 & $\begin{array}{l}\text { Band formed by a Meckel's } \\
\text { diverticulum }\end{array}$ & Days. & Mr. Dent & D. & $\begin{array}{l}\text { No action of bowels after operation; bowel above constriction } \\
\text { in an incipient state of gangrene; operation } 3 \text { days after admis. }\end{array}$ \\
\hline $\begin{array}{l}\text { 2. W. D. } \\
\text { 3. F. M. }\end{array}$ & 27 & Feb., 1889 & Band formed by mesentery & 3 & Mr. Pick & D. & $\begin{array}{l}\text { sion (8 days of constipation). } \\
\text { Gut gave way at operation. }\end{array}$ \\
\hline 4. E. G. & - & Sept., 1893 & and diverticulum & 6 & Mr. Dent & D. & $\begin{array}{l}\text { case too complicated for successful treatment. } \\
\text { Gut gave way and an artificial anus formed : gut above the con- }\end{array}$ \\
\hline 5. L. G. & 65 & Feb., 1892 & & & & D. & $\begin{array}{l}\text { striction was gangrenous; operation too late. } \\
\text { Gut gave way and was resected; very collapsed at time of opera- }\end{array}$ \\
\hline 6. J. W. & 30 & Mar., 1893 & Meckel's diverticulum & 3 & Mr. Dent & D. & tion: operation too late . \\
\hline 7. E. $\mathbf{H}$. & 49 & Feb., 1894 & Band & 3 & Mr. Sheild & D. & $\begin{array}{l}\text { A band found and divided ; gut ulcerated by it ; incised, emptied, } \\
\text { and sewn up; survived 4 days, but no action of bowels; another } \\
\text { band was found post mortem, not tightly constricting the gut; } \\
\text { operation on day after admission, fourth day of constipation. }\end{array}$ \\
\hline 8. J. P. & 13 & Sept., 1891 & Meckel's diverticulum and & 3 & Mr. Pick & R. & \\
\hline $\begin{array}{l}\text { 9. J. T. } \\
\text { 10. E. J. }\end{array}$ & $\begin{array}{l}28 \\
37 \\
46\end{array}$ & $\begin{array}{l}\text { Feb., } 1893 \\
\text { July, } 1893 \\
\text { Feb., } 1894\end{array}$ & $\begin{array}{l}\text { Two or three bands } \\
\text { I ong band } \\
\text { Band }\end{array}$ & $\begin{array}{l}3 \\
2 \\
3\end{array}$ & $\begin{array}{l}\text { Mr. Haward } \\
\text { Mr. Dent } \\
\text { Mr. Haward }\end{array}$ & $\begin{array}{l}\mathbf{R} . \\
\mathbf{R} \\
\mathbf{R}\end{array}$ & Peritoneai cavity drained for the first 24 hours after operation. \\
\hline
\end{tabular}

TABLE IV.-Laparotomy for Stricture of Bowel-All Fatal.

\begin{tabular}{|c|c|c|c|c|c|}
\hline Name. & Age. & Date. & Nature of Case. & Surgeon. & Remarks. \\
\hline $\begin{array}{l}\text { 1. A. L. } \\
\text { 2. J. L. } \\
\text { 3. G. J. } \\
\text { 4. G. L. } \\
\text { 5. W. H. } \\
\text { 6. W. S. } \\
\text { 7. E. B. }\end{array}$ & $\begin{array}{l}69 \\
42 \\
40 \\
63 \\
- \\
52 \\
17\end{array}$ & $\begin{array}{l}\text { Nov., } 1891 \\
\text { Feb., } 1891 \\
\text { June, } 1891 \\
\text { June,1893 } \\
\text { Mar., } 1894 \\
\text { Mar., } 1894 \\
\text { April, } 1894\end{array}$ & $\begin{array}{l}\text { Old polypus, nearly closing } \\
\text { tbe small intestine } \\
\text { Schirrus of jejunum } \\
\text { Malignant stricture of colon } \\
\text { Malignant stricture of rec- } \\
\text { tum } \\
\text { Malignant stricture of sig. } \\
\text { moid flexure } \\
\text { Stricture, probably malig- } \\
\text { nant, of sigmoid flexure } \\
\text { ? }\end{array}$ & $\begin{array}{l}\text { Mr. Haward } \\
\quad- \\
\text { Mr. Dent } \\
\text { Mr. Pick } \\
\text { Mr. Dent } \\
\text { Mr. Haward } \\
\quad-\end{array}$ & $\begin{array}{l}\text { Inguinal colotomy was attempted, but the colon was flaccid; so the } \\
\text { small intestine was drawn up, and an artificial anus formed. } \\
\text { The operation was more exploratory than effective. He died more } \\
\text { than a month afterwards of pneumonia. } \\
\text { An artificial anus was formed. Death soon after operation. } \\
\text { The seat of stricture was not discovered. An artificial anus was } \\
\text { formed. } \\
\text { A band was found constricting the cæcum, and divided ; hut it was } \\
\text { recognised that this had not produced total obstruction. He died in } \\
\text { a few hours. } \\
\text { The bowel was opened above the constriction, and fixed to the } \\
\text { abdominal wall. } \\
\text { This youth died a few hours after operation. There was no post- } \\
\text { mortem examination, and the notes are mislaid. It is believed to } \\
\text { have been a case of stricture of the bowel. }\end{array}$ \\
\hline
\end{tabular}

lapping round the pylorus, and causing obstruction. The operation therefore was performed merely with the hope of prolonging life, and rendering it more tolerable. In this it succeeded completely. He returned here to die in Feb. ruary of this year. I produce the preparation from this case also.
The other patient was also operated on by Mr. Bennett. He was lately in the hospital, having then enjoyed twenty months of tolerable health and active life. When the operation was performed, he was so reduced that he seemed almost moribund. His weight increased after the operation from 6 st. 11 lbs. to 10 st. 2 lbs. 
LAPAROTOMY FOR OBSTRUCTION.

We now come to the extensive and difficult class of cases in which laparotomy is performed for the relief of obstruction, the exact cause of which can in most cases only be conjectured. The success of the operation depends in a great measure on the anatomical cause of the obstruction, and in a great measure also on the promptitude of the operative interference. In my younger days, though the possibility of recovery was admitted and the operation was occasionally practised, nay, though possibly a few successful operations had actually been performed, it was looked on as a desperate measure, and was therefore almost always delayed too long ; so that all the operations which I have myself practised, or which my colleagues performed during the period of my service here, were I believe unsuccessful. Now, however, we have a very different tale to tell; and though in some of the classes of obstruction we can still report no success, in others the percentage of recovery has been so encouraging as to inspire the surgeon with fresh hope, and to give fresh motives to both physician and surgeon for a more extensive and more careful study of the symptoms.

Cases of internal obstruction may be divided into (1) from the pressure of tumours; (2) from intussusception; (3) from volvulus or kink; (4) from bands crossing the intestine: (5) from stricture : (6) from hernia not perceptible externally: (7) from the lodgment of foreign bodies; of which last there are no examples in this list.

1. Total obstruction from the pressure of a tumour is of rare occurrence, but a case was spoken of in a former lecture in which an enlarged mesenteric gland so pressed on the Sowel as to stop its action. Abscesses and hydatids often cause more or less obstruction, but this is seldom total. Gall tones, again, may produce obstruction, directly by impaction in the gut, or indirectly by exciting volvulus, but no such case is included in our list. I must refer you on this head to Mr. Mayo Robson's interesting paper lately read at the Royal Medical and Chirurgical Society, and to the discussion which followed.

2. The operative treatment of intussusception has not, in our experience, been successful. Most of the cases which I have found occurred in very early life. The infants were all admitted when in an advanced condition of the disease, and, as the operation was in all cases performed at once, the surgeon had not to reproach himself with any delay. Table I contains the leading particulars of these cases.

There was also another case, classed with those of volvulus, in which there was an intussusception produced by an intestinal polypus.

3 Our cases of laparotomy for kink and volvulus are shown in Table II.

4. Intestinal Strangulation by Bands.-The next class of cases of obstruction consists of those in which the bowel is strangulated by one or more bands crossing or encircling it, such bands being formed by a Meckel's diverticulum, by a peritoneal adhesion or adhesions, by a string of adherent and condensed omentum, or by some other structure of limited extent, such as an appendix epiploica adherent to a neighbouring appendix or coil of intestine. We have had numerous instances of this form of obstruction, and I think everything tends to show that if the case be dealt with sufficiently early, a good result may be fairly anticipated from surgical interference. On the other hand these bands are often very tense, and cut into the substance of the bowel rapidly; and if the bowel is inourably damaged, its resection introduces a formidablecomplication into the case, while frequently the patient's condition is not such as to permit so prolonged an operation, and then an artificial anus must be formed. But the more one sees of cases of laparotomy, the more strong I think will become the conviction of the undesirability of an artificial anus. It seems far better, if there is any chance of the patient's survival, to resect even a considerable portion of intestine and mesentery. Mr. Harrison Cripps has, however, recorded a most interesting case in which, after the formation of an artificial unus, a permanent cure was effected by the resection of a foot of intestine. The patient, he informs me, is now in perfect health a year after the operation.

\footnotetext{
a British Medical Journal, November 17th, 1894
}

We may then sum up our past experience of laparotomy for this form of obstruction thus. There have been 11 cases, of which 7 proved fatal. In 4 of these fatal cases the operation was evidently too late, the period of strangulation being five, seven, six, and eight days respectively : and the need for the promptest possible operation in such cases is shown by the fact that in the 3 other cases in which the period of strangulation was only three days. in each the gut had been fatally injured, so that it gave way. In one of these cases the lesion proved at once fatal, in the others an attempt was unsuccessfully made to remedy it-in the one case by the resection of the injured bowel, in the other by incision of the gat and evacuation of of its contents, followed by suture. In the four successful cases, the period of strangulation did not exceed three days. (See T'able III.)

I cannot do better than direct your attention to a most interesting paper by $\mathrm{Mr}$. Dent, ${ }^{2}$ founded in part upon some of these cases. Mr. Dent dwells with just emphasis on the need for an accurate study of the symptoms, which are usually sufficient to establish a pretty confident provisional diagnosis, and on the absolutely imperative duty of the surgeon in all such cases to lose no time in operating. He gives, also, a graphic picture of the processes by which the rapid disintegration of the bowel is effected, and lays down most valuable rules for the operation and after-treatment.

5. Obstruction from Stricture. - Laparotomy for stricture of the bowel is a far less promising proceeding, for the stricture is often malignant, and frequently also the diseased portion is so extensive as to preclude all idea of its removal, and then the only thing that can be done is to form an artificial anus or to implant the bowel above the stricture into a lower coil of intestine. Very commonly also in hospital practice the symptoms have been too indefinite to induce the patient's medical attendant to send him in until the condition is too far advanced to have much chance for success from any surgical proceeding.

The number of cases operated on was only 7, but they all proved fatal. In one case, however, the operation seems to have had nothing to do with the death, which occurred more than a month afterwards from pneumonia. (See Table IV.)

6. Strangulation of an internal hernia, that is, a hernia not perceptible by external examination, bears the strongest analogy to strangulation by a band. We have 4 cases on our record, only one of which was successfully dealt with. This was the case of a man under Mr. Sheild's care last September, in whom the bowel was strangulated in a hole in the mesentery. In this case there was also an inguinal hernia, but it was rightly believed not to be strangulated, so that no time was lost in exploring it. Two of the other cases were small Littre's herniæ, strangulated in or near the abdominal ring; the strangulation was relieved, but the patient was seen too late for the operation to be effectual. In the fourth case the notes are not sufficiently precise to enable me to give you exact particulars.

The only case I have found of resection of the intestine for gangrene after hernia was a desperate one, and terminated fatally, as was inevitable. The woman, aged 58, had had a femoral hernia, which seemed to be perfectly reducible on her admission, though there was a history of strangulation for several days, and of repeated and violent taxis. As stercoraceous vomiting came on the day after admission, it was decided to explore the abdomen in case the hernia had been reduced en masse. The cæcum was found gangrenous and was resected, but the patient was in too weak $a$ condition to rally from the operation, and died next day.

I have so far fulfilled the task which I set before myself, and have given you as complete a statement as I can of the experience of St. George's Hospital in this important department of medicine and surgery. But I must ask your patience for a few minutes while I venture on some observations on the general question of laparotomy, as seen in the light of this experience.

In the first place, it is obvious that there are many conditions, necessarily fatal if left alone, which are susceptible of cure by operation. Those which this series exemplifies are intraperitoneal rupture of the bladder or intestine, freely perforating ulcer of the stomach or duodenum, internal strangulation, and internal hernia. These conditions admit 2 BRITISH MEDICAL JOURNAI, January 20th, 1894. 
of relief only by operation, and though internal strangulation may be palliated by enterostomy, none of them can be cured except by laparotomy. I think, then, that the opinion of the surgical world will be unanimous in saying that such cases should be treated in that manner; and, if so, it follows as a matter of course that the operation should be performed at the earliest moment possible, since peritonitis comes on with extreme rapidity, and very soon the condition will be hopeless. Again, there are other conditions which perhaps can hardly be said to be necessarily fatal, but which are so dangerous to life that they may be practically regarded as incurable without operation. This may be said of acute diffused peritonitis from perforation of the appendix, and of subphrenic cavity from gastric or duodenal perforation. Here, again, it seems to me hardly to admit of argument that laparotomy is urgently indicated; and we have had ample evidence that the fatal results of delay are only a little less rapid in this than in the former class.

Another category may be formed of cases which admit, indeed, of cure by laparotomy, but not without great risk, and which are not necessarily fatal, at any rate for the moment. I speak of idiopathic and tuberculous peritonitis, of intussusception, of obstruction from kink or volvulus and of internal stricture. The nearer these latter approach to total stoppage or strangulation the more urgent is the indication to operate; but surgical opinion, and perhaps medical opinion to a still greater extent, is as yet divided as to the propriety of early interference in such cases, though it is impossible to doubt that if relief is not obtained by medical and mechanical treatment the delay will seriously prejudice the chance of success by laparotomy.

Next we have cases of hydatid cysts, of pancreatic cyst, of other non-cancerous tumours, and of limited abscess in the abdominal cavity. The danger that such tumours will make their way into the general cavity of the peritoneum is very great, the patient's prospect of recovery is very much diminished if diffuse peritonitis has been thus set up, and the treatment by laparotomy is so very successful if undertaken before this has occurred, that I cannot myself doubt that early operation is a duty.

In cases of cancerous tumour or stricture it is doubtful whether the total excision of the tumour or of the viscus affected is worth its risks; but it is often possible to maintain nutrition and so preserve life by some "short circuiting" operation, of which gastro-jejunostomy is the most familiar example.

Finally, there are the cases of cholecystotomy and other operations on the gall bladder, operations performed on the ordinary surgical indications, for relief of pain and deliverance from future danger; and, as it seems, with no more than the usual risk and no less than the usual guarantee against recurrence.

If, however, it is so important in many cases to save hours, even minutes, of delay, are our hospital arrangements the best calculated to secure this end? Some surgeons have suggested that in cases requiring laparotomy "consultants should pass a self-denying ordinance, and leave the operation in the hands of the general practitioner." I cannot too strongly dissent from this suggestion. Delay involves great dangers, doubtless; but these operations are among the most difficult in surgery, and require, as Benn ${ }^{3}$ has most truly said, that he who undertakes them should be "no tiro in surgery:" and the diagnosis requires also "no tiro in physic." That an operation can be better decided on and better performed at the hospital than at the patient's house, seems to me undeniable; and we may hope that as the fatal effects of loss of time become better understood the patients may be sent in earlier. Excluding tranmatic cases, they should, I think, be still, as before, physicians' patients, but the house-physician might be instructed to send for both physician and surgeon immediately on the patient's admission, so that the consultation could be held without any further loss of time, and the operation performed, if necessary, on the spot.

If $\mathrm{I}$ were still in the active pursuit of operative surgery, and had thus taken a part in the noble surgical exploits about which I have been speaking, I should have become familiar with the details on which the success of these operaIntestinal surgery, p. 31, edition, 1889. tions so much depends, and which have been so greatly modified of late, and so much improved. But alas! my most recent experience of laparotomy is nearly eight years old, and the whole proceeding has been revolutionised in that time. I cannot therefore speak with any authority on that subject; nor is it necessary. Treating of laparotomy for diffuse septic peritonitis, Mr. Lockwood (in the current volume of the Med. Roy. and Chir. Trans.) has given what seem to me admirable directions for the details of such cases. He has treated of the methods of stimulating the patient and eombating the collapse before operation by subcutaneous injections and by alcoholic enemas, of the application of local warmth during the operation, of the kind of anæsthetic to use of the necessity in some cases for evacuating the contents of the distended and semi-paralysed bowel by incision, and suturing the intestine (of which I have given you two instances from Mr. Sheild's practice), of the great assistance which is often found in these operations from a stout suture passed through the abdominal parietes on each side to hold the incision open, and avoid the embarrassment of retractors, a device for which we are indebted to $\mathrm{Mr}$. Sheild; to the order in which the search should be conducted through the intestinal contents in seeking for perforation or obstruction; to the method of protecting the intestines, which have to be withdrawn out of the abdominal cavity; to the method of washing out the peritoneum, and carefully separating the adherent intestines; to the union and drainage of the wound, the care of the patient during the operation, and his treatment and feeding afterwards. Certainly the perusal of $\mathrm{Mr}$. Lockwood's paper will lead all readers to agree with Senn that these operations are not the part of a "tiro in surgery;" while both the accessories of the operation, and the requisites for after-treatment, require the best resources of a great establishment, where every means of treatment is ready, and there are plenty of skilled persons to apply them.

The only matter which did not come within the scope of Mr. Lockwood's paper, as far as I can see, is the method of intestinal resection and suture; but this I do not venture to treat of. Operating surgeons alone are competent to judge of the value of the various contrivances recently introduced for obtaining safety in removing portions of irretrievably damaged bowel, and speed combined with security of adaptation in the reunion of its divided parts; and the time has not yet been sufficient for any consensus of opinion on the subject.

\section{NOTES ON THE LIMERICK FOOD POISONING} CASES.

By Sir CHARLES A. CAMERON, F.R.C.S.I., Professor of Chemistry and Hygiene, Royal College of Surgeons in Ireland; M.O.H. Dublin.

THE following brief account of this sad case may interest the readers of the British Medical Jodrnal : On July 3rd, 1895 , about 70 inmates of a convent and boarding school in Limerick became very ill after dinner, and for several days suffered from vomiting and purging of a severe character. Three ladies died, and many of the other inmates were for several days in a precarious condition. Poison being suspected, portions of the vomit and dejecta were sent to me for examination on July 5th; also a portion of cornflour which it was suspected might contain poison-but none was found in it, nor in the other matters sent to me. Suspecting the case to be one of ptomaine poisoning, I telegraphed for portions of everything the patients had for dinner; but the only items available were sugar and sodium bicarbonate, both of which were pure. It has been clearly ascertained that the poison was not in the meat used, for some persons who had partaken of it were not ill, and the history of the carcass that furnished it was made out and negatived the hypothesis of unsoundness or disease in it. It appears that a custard formed part of the dinner, and that all who partook of it sickened. The cook (one of the sufferers) states that she prepared the custard as follows :

Tuesday, Julv 2nd, I took 4 quarts of skimmed milk of previous night, boiled it, added about $\frac{1}{2} \mathrm{lb}$. loat sugar, added 2 tablespoonfuls of cornflour, and boiled again; this was done in a tin vessel. At 3 or 4 P.M. resumed making of custard: Beat up 8 or 10 eggs, all fresh except one. 